\title{
The Conceptualization of the Performance Elements of M edia Organizations and the Factors that Influence their Performance
}

\author{
Jisuk Woo,* Hyunki Shin,*** and Jeong Min Choi****
}

\begin{abstract}
This study aims to examine the concept of media organizations' performance and the factors that influence their level of performance. Media organizations are often private profit-seeking enterprises but at the same time also have a public side that realizes freedom of speech, which is a core value of democracy. Therefore, a theory of media organizations' organizational performance needs to reflect this duality. We divide media organizations' organizational performance into two categories: economic-industrial and sociocultural. Economic-industrial performance can be defined as how media organizations perform in the market. A typical indicator is how much sales revenue they bring in. In addition, because their revenue heavily depends on advertisements, newspaper subscriptions or television viewer ratings, which are directly connected to advertisement revenue, can be used as performance indicators.

Sociocultural performance refers to how media organizations perform with respect to their content. A media organization's sociocultural performance primarily depends on whether it has accomplished the goals indicated by relevant laws. In addition, sociocultural performance depends on how the contents of a media organization are received by its readers or viewers, which can be identified by media credibility measures that are conducted by many organizations. Factors that influence media organization's performance include independence, diversity and openness. The present study is a preliminary attempt to provide a conceptual analysis as groundwork for empirical research. We hope this preliminary examination builds a foundation for comparative studies of diverse public organizations such as public hospitals, universities, and public enterprises and can contribute to further theoretical and conceptual discussions about organizational performance.
\end{abstract}

Keywords: media organization, sociocultural performance, audience trust, independence, diversity, openness

* Jisuk Woo is Professor, Graduate School of Public Administration, Seoul National University.E-mail: jisuk@snu.ac.kr.

** Hyunki Shin is Lecturer, Graduate School of Public Administration and Social Welfare, Kyonggi University. E-mail: nollstshin@gmail.com, Corresponding author.

*** Jeong Min Choi is Adjunct Professor, Graduate School of Public Policy, Sogang University. E-mail: mingg11@gmail.com.

Manuscript received July 24, 2016; out for review July 30, 2016; review completed August 25, 2016; accepted August 29, 2016.

The Korean Journal of Policy Studies, Vol. 31, No. 3 (2016), pp. 27-45.

(C) 2016 by the GSPA, Seoul National University 


\section{INTRODUCTION}

This study investigates the theoretical and legal concept of media organizations' performance, and examines the factors that influence their organizational performance, based on their distinct characteristics that are different from other public and private institutions. The overseeing of national affairs is shifting from government-centered operations to a public-private partnership, due to the diversification of government roles and functions. Accordingly, there is growing interest in the question of role allocation between the public and private sectors, the role and performance of the private sector that is increasingly taking over the previously governmental functions, and proper measuring methods of the organizational performance of this new private sector that functions as government agencies.

Media organizations are often private entities, but they are required to play a publicsector role. As it is difficult to draw a clear line between typical public organizations and typical private organizations, the mainstream research on organizations in the field of public administration has also focused more on the general characteristics and performance of these organizations than on the differences between public and private organizations. However, if the differences between public and private organization are not well identified, it will be difficult to understand how these organizations operate and generate their output and to know how to evaluate their performance. Understanding the differences between various organizations is especially important given that governmental functions are increasingly being performed by different organizations that have different degrees of publicness or privateness. The way the public-private distinction has been theorized in the field of public administration has shed a guiding light on organizational characteristics and the structure and performance of organizations (Perry \& Rainey, 1988; Rainey \& Bozeman, 2000; Chun, 2009).

The performance of public organizations is usually composed of three dimensions (the so-called "3E"s): effectiveness, efficiency and equality. However, in the case of media organizations, the fact that their ultimate goals are to pursue profit in the market as a private organization and to realize the constitutional value of free speech using public property (for example, radio waves) at the same time, makes them different from typical public organizations.

The perspectives from which one can look at media organizations can be divided into two: a market-based perspective that sees them as private entities that pursue profit in the market, and a public interest perspective that sees them as a special entity to be deemed to realize the freedom of speech, which is the core value of democracy. Along with such two conflicting perspectives on media organizations, their performance can be also categorized as economic-industrial performance that emphasizes profit-making 
in the market and sociocultural performance that highlights their public function of realizing the freedom of speech and people's right to know in a democratic society. Based on a general model of organization performance, the economic-industrial and sociocultural performances are understood to be in line with management performance and program performance, respectively (Selden \& Sowa, 2004).

This study aims to explore theoretical and legal concepts of media organizations' organizational performance and examines the factors that influence it. We hope that this preliminary examination provides a foundation for comparative studies of diverse public organizations such as public hospitals and universities and contribute to further theoretical discussions and empirical studies about organizational performance.

\section{THE THEORETICAL CONCEPT OF ORGANIZATIONAL PERFORMANCE}

The administrative reform inspired by new public management movement in academia and the ensuing emphasis on making government organizations accountable for their performance has led to an increased interest in organizational performance, and various studies on organizational performance and the factors influencing performance have been carried out (Jeong \& Lee, 2012). Public organizations' performance refers to the output of government activities that are implemented to provide administrative services to people. However, it is not easy to conceptualize organizational performance, as it is the result of the social construction. The difficulty in conceptualizing and measuring the performance of public organizations is compounded by the fact that public organizations tend to have more diverse stakeholders who demand various kinds of performance according to their different interests (Boschken, 1994).

Organizational performance can be understood from two perspectives, either in terms of a production process of inputs and outputs or in terms of the public value generated by an organization. From the perspective of the production process, organizational performance includes efficiency, which is the ratio of output to input, and effectiveness, which is the degree of achievement of output goals. Kwon and Im (2003) define organizational performance as efficiency, effectiveness, and fairness and analyze how they are affected by organizational culture, human resource management, leadership, organizational citizenship behavior, public service motivation, and administrative reform. Kim and An (2006) analyze how the organizational performance of the Ministry of Government Affairs and Home Affairs is understood in terms of efficiency, effectiveness, and responsiveness was affected by the structural changes in the structure of the organization, changes in the way conflict management was handled, and institutional 
changes in the evaluation process and human resources matters. An (2008) examines the relationship between organizational culture and organization performance, measuring it in terms of efficiency (such as improving the output-to-input ratio via budget cuts and layoffs) and effectiveness (such as expanding the scope of administrative services and improving the quality of policy and administrative services) in 50 central government agencies in Korea.

Conceptualizing organizational performance as efficiency and efficacy is often criticized by scholars who embrace the public value perspective on the grounds that it disregards other important public values such as probity, fairness, and reciprocity that are related to "process values" and reliability that is related to "regime values" (Van Dooren, Bouckaert, \& Halligan, 2015; Hood, 1991). Wang defines organizational performance as a "multidimensional concept" comprising "efficiency, which can be identified through administrative/operational functions to maximize the output from the input of limited resources in terms of services produced and provided by an organization and its members," "effectiveness, which is identified by the degree of goal achievement and service quality," and "equality, which includes the concept of satisfaction" (2007, p. 68). There are two forms of equality: distributive equality, which refers to the extent to which employee compensation matches that of comparable organizations, and procedural equality, which refers to how fair the members of the organization perceive the compensation process to be (2007, p. 68).

We have examined concepts of organizational performance defined by various scholars and different approaches to measure the organizational performance. In the next section, we will take a closer look at how organizational performance should be defined in public organizations.

\section{ORGANIZATIONAL PERFORMANCE IN PUBLIC ORGANIZATIONS}

Some researchers claim that the concepts of the publicness, democratic responsibility, and democracy should figure into an assessment of public organizations' performance (Erkkila, 2007; Kljin \& Skelcher, 2007; Sorensen, 2002). Previous studies of government performance have mainly focused on management performance (budget efficiency, human resources management efficiency, etc.) and policy performance.

However, there have been attempts to measure the quality of policies and programs promoted by the government applying the concept of publicness. Jeong (2010) categorized such publicness as "substantive publicness," emphasizing whether policies or programs were fairly and universally provided to people, and "procedural publicness," 
emphasizing whether fair procedure and citizen participation were realized in the process of implementing such policies or programs. Substantive publicness is composed of (1) equality of services for customers, (2) equality of personnel management in an organization, (3) investment in the socially disadvantaged, (4)a procedural system for the socially disadvantaged, with respect to equality aspects, and (5) customers' rights stipulated in laws, with respect to universality aspects. Procedural publicness comprises transparency and openness, participation of external stakeholders, responsiveness, and bureaucratic accountability.

Accountability for public organizations is more complicated than it is for private organizations owing to the more diverse philosophical, legal and organizational characteristics of public organizations. The most common understanding of the legal and ethical duties of public institutions is theoretically rooted in work of Herman Finer, who emphasized external control by the National Assembly or judicial power in the 1940s, and Carl Friedrich, who stressed bureaucrats' internal accountability (Finer, 1941; Friedrich, 1940; Romzek \& Dubnick, 1987; Roberts, 2002; Ospina, Grau, \& Zaltsman, 2004). Studies since then have further developed the idea of bureaucrats' internal accountability and external control or have additionally emphasized the aspect of public service customers.

Hoek, van Montfort, and Vermeer (2005) divide public organizations' accountability into "vertical accountability" (accountability to a higher authority and supervisory entities), "internal accountability" (accountability to internal management, control and performance systems), "customer accountability" (accountability to customers who consume the products and services), and "social accountability" ( accountability for the public). Kwon, Hwang, An, and Park (2009) have measured vertical accountability, internal accountability, customer accountability, and social accountability in different types of public organizations in Korea, and Park (2010) has conducted a detailed analysis of the internal accountability of public organizations.

In the case of media organizations, the credibility of sources and the grounds on which news reporters support their clams is critical. The KCSC (Korea Communication Standards Commission) regulates media organizations and imposes sanctions when the organizations do not comply with the rules provided by relevant laws and regulation. The KCSC even ordered Channel A, a recent addition to the general broadcasting industry in Korea, to "apologize to viewers" in 2012 (Ha, 2014). Such disciplinary actions taken against media organizations demonstrate the importance of customer accountability and social accountability of media organizations.

Thus media organizations' performance cannot be easily analyzed by drawing on general concepts of organizational performance or even on concepts pertaining to public organizations' performance. A theory of media organization performance 
requires taking into account the dual nature of media organizations as profit-seeking entities and as public organizations that enable freedom of speech and honor the people's right to know. Furthermore, since the degree of publicness in different media organizations varies depending on the differences in ownership, funding sources, and political control, the relationship between the degree of publicness of media organizations and their organizational performance is also worth pursuing. We turn to these topics in the next section.

\section{ORGANIZATIONAL PERFORMANCE OF MEDIA ORGANIZATIONS}

There are limitations in applying the "3Es (efficiency, effectiveness, equality)" to the concept of organizational performance of media organizations. In addition, differences among media organizations should also be considered. For example, broadcasting organizations that use the public property such as radio waves and are presumed to have a strong social influence have been demanded to have more public responsibility than newspapers (Kim, 2003). Thus the need to develop the concept of organizational performance and the indicators that can measure the performance level of media organizations based on the full understanding of their distinct characteristics is prominent.

We focus in this article on Korean media organizations, which according to the 2014 annual report of the Korea Press Foundation, includes newspapers, broadcasting organizations, internet newspapers, and news agencies. Newspapers include numerous subcategories, such as national general dailies, sports dailies, national general weeklies, and so forth. Broadcasting includes public and private organizations as well as terrestrial DMB. Internet newspapers include general, local, and specialized forms. ${ }^{1}$

The economic-industrial performance focuses on how newspapers and broadcasters perform in the market. Media organizations are generally seeking to create the maximum profit in the market (Lee, 2008; Kim, 2011), and the need for profit-making increases as the media environment is rapidly changing and the prevalence of new media such as Internet poses great challenge to the old media. Competition in the media industry intensifies as the convergence of media occurs and the boundaries of different media are becoming more and more blurry. All of these changes mean that media organizations face imminent need to strengthen their competitiveness by securing financial resources and content quality. A crucial indicator of economic-industrial performance

1. As of 2013, the number of media organizations in Korea totaled 3,686 and the number of employees was 51,883 . Total annual sales were $\$ 8.6191$ trillion. 
in newspapers and broadcasting organizations is sales, and given that media organizations' revenue greatly depends on advertisements, subscription rates and viewer ratings that are directly related to advertising revenue are also an important indicator of performance.

Sociocultural performance refers to the quality of media contents and their effects on the users (Lee, 2008). An essential indicator of sociocultural performance is whether the media organizations have realized their goals or beliefs through their mission. In particular, as media organizations are regulated by relevant laws due to their public function of pursuing the freedom of speech and people's right to know, their sociocultural performance can be primarily evaluated by identifying whether they have accomplished goals and ideas stipulated in laws and regulations.

Establishing concepts and measurement indicators for the economic-industrial performance of media organizations is not be difficult, as we can apply the general concepts and measurements that have already been developed, but the concept of sociocultural performance of media organizations has yet to be fully examined. We turn next to media organizations' sociocultural performance, paying special attention to the laws and regulations that govern media organizations in Korea.

\section{Policy Goals Stipulated in Press Laws}

Media organizations are the critical system of democratic regimes for realizing a core value of democracy: the freedom of speech. However, because freedom of speech needs to harmonize with the responsibilities and limitations of a free press, the policy goals media organizations need to pursue are specified in press laws. Therefore, their sociocultural performance is directly connected to the question of how well they accomplish the policy goals stipulated in press laws. We explore the policy goals of newspapers and broadcasting organizations by analyzing the 'Newspaper Act' and the 'Broadcasting Act.'

To begin with, newspapers' policy goals are stipulated in the "Newspaper Act" (Act on the Promotion of Newspapers, etc.). First, Article 1 of the Newspaper Act proposes the following as its purposes: i) the freedom and independence of publication, ii) the freedom of press, iii) social responsibility, and iv) the formation of the public opinion. Second, regarding the freedom of speech of newspaper companies, Article 3 identifies it as i) a right to freely access information sources and ii) the freedom to freely publish covered information. Also, Article 4 defines the freedom of speech as the freedom and independence of editing. Third, regarding newspaper companies' social responsibility, Article 3 stipulates that they shall respect i) the dignity and value of human beings and ii) democratic basic order; Article 6 states that the editing and 
production of newspapers shall iii) conform to the interests of their readers.

In order to ensure that newspaper companies accomplish their policy goals (or organizational performance), the government has implemented ex-post regulations such as ownership restrictions and a public opinion concentration survey, and has devised to develop and promote the newspaper industry. Regarding regulations, Article 18 of the Newspaper Act prohibits large enterprises and their affiliates from owning more than $50 \%$ of a newspaper company. At the same time, Article 17 stipulates the investigation of the degree of concentration of public opinion of newspapers, online newspapers, online news services, and broadcasting (television broadcasting, radio broadcasting and mobile multimedia broadcasting). Ownership restrictions and the investigation of the concentration of public opinion can be regarded as specific measures to prevent newspapers from monopolizing public opinion and to guarantee diverse public opinions. In addition, with respect to the promotion of the newspaper industry, the Newspaper Act stipulates the establishment of the Korea Press Foundation and the Korea Press Fund.

Next, the policy goals that need to be pursued by broadcasting companies are specified in the Broadcasting Act. First, the Broadcasting Act stipulates its purposes in Article 1: i) the freedom and independence of broadcasting, ii) ensuring viewers' rights and interests, iii) a democratic formation of public opinion, and iv) contributing to the enhancement of public welfare and the development of broadcasting by improving the national culture. These are not only the purposes of the Broadcasting Act but also of broadcasting companies, and the four policy goals mentioned above can be interpreted as elements composing the public interest in broadcasting (Yun, 2013).

Second, Article 3 of the Broadcasting Act states that broadcasting business operators shall enable their viewers to participate in decision-making regarding planning, programing and producing broadcast programs, and shall assure the broadcasting results conform to their viewers' interests. Third, Article 4 emphasizes that the freedom and independence of broadcast programming shall be guaranteed. Fourth, Article 5 defines the public responsibility of broadcasting as i) respecting the dignity and value of human beings and democratic basic order, ii) contributing to the unity of the public, a harmonious development of the country and a democratic formation of public opinion, and restraining from promoting any discords among regions, generations, classes and sexes, iii) restraining from injuring other's reputation or infringing on other's rights, iv) restraining from promoting crimes, immoral conducts or speculative spirit, and v) restraining from promoting lewdness, decadence or violence.

In particular, with regard to the public responsibility of broadcasting, Article 6 additionally specifies nine types of public responsibilities of broadcasting, which include i) fairness of reporting, ii) prohibiting discrimination in broadcast programming, 
iii) respecting the ethical and emotional sentiments of the public, iv) protecting and extending the public's right-to-know and freedom of expression, v) protecting minority groups, vi) contributing to the balanced development of local communities and promoting national cultures, vii) extending their social education function, viii) propagating the standard language and endeavoring to refine and purify the language, and ix) providing an equal opportunity to express different opinions.

To realize such policy goals, the Broadcasting Act stipulates various regulations as follows: restrictions on ownership (Article 8), license renewal (Article 17), a broadcast evaluation committee (Article 31), deliberation on impartiality and the public nature of the broadcast (Article 32), a viewers' rights protection committee (Article 35), a broadcasting dispute conciliation committee (Article 35-3), a media diversity promotion committee (Article 35-4), programming of broadcast programs (Article 69), restrictions on share of audience (Article 69-2), guaranteeing general viewing and listening rights (Article 76), and establishing a viewers' committee (Articles 87, 88).

The social responsibility of broadcasters outlined in the Broadcasting Act is more diverse and more concretely defined than that of the newspapers outlined in the Newspaper Act. Also, while only a few restrictions are imposed on newspapers, restrictions on broadcasting are more detailed and meticulous. This is because broadcasters monopolize limited resources_radio waves_and are assumed to exert a relatively greater social influence. In particular, the Broadcasting Act highlights the social responsibility of broadcasting companies through the social responsibility article (article 5) and the fairness and public interest article (article 6).

Ultimately, media organizations' sociocultural performance is related to how faithfully they accomplish their purposes, social responsibilities, and in the case of broadcasting, the demand for fairness and public interest. As possible means to measure this, the frequency of sanctions or other disciplinary measures imposed on media organizations by regulators may be used. In addition, how media contents that reflect such demands are accepted by the audience is directly related to media organizations' sociocultural performance. The following section contemplates the elements of media organizations' sociocultural performance in detail.

\section{Public Interest, Fairness, and Audience Trust}

While the demand for fairness and attention to the public interest is much stronger for broadcasting than newspapers, it is possible to apply the concept of the public interest to newspapers given that newspapers also have a political function.

There are two conflicting theories of the public interest: public interest substance theory and public interest process theory (Kim, 2008). Public interest substance theory 
insists that there is public interest that transcends private interest that is grounded in a moral imperative or common interest. Public interest process theory, by contrast, denies the existence of the objective public interest claimed by the substance theory and claims that the public interest is created through mutual conflict and mediation among various private interests. From this perspective, the public interest can be understood as a procedural concept, which is used as a legal or ideological symbol by various political interests (Kim, 2008). The idea of the public interest can be further defined in terms of regionalism, the free marketplace of ideas (in which diversity and competition figure), and universal service (Napoli, 2001) as well as in terms of political welfare, social welfare, and economic welfare (Cuilenburg \& McQuail, 2003).

Kim (2008) criticizes what he sees as the abstract and ideological features of the concept of the public interest and has proposed a concept of public accountability that he maintains is descriptive and practical, taking into account organizational/structural accountability in which the public interest is served, managerial/procedural accountability in which autonomy from capital is secured, and functional accountability in which socially integrative and universal programs and services are provided.

Especially important in the Korean media environment are issues related to the fairness of media organizations. Media organizations are in charge of producing and distributing information necessary for maintaining a democratic society and creating public opinion. Many media scholars contend that the reason Korean media organizations find themselves the target of public criticism is that they are highly partial (Rhee $\&$ Choi, 2005). These scholars also claim that the essence of the crisis that many media organizations in Korea are facing now is one of trust, the consequence of their lack of fairness in the presentation of news. According to this argument, the current crisis is not only caused by the business difficulties that have been the fallout of a rapidly changing market environment but also by the dissatisfaction of viewers and readers who have turned away from media that in failing to provide unbiased reporting has failed to perform its social role (Rhee \& Choi, 2005).

The definition of fairness especially in news reporting has been examined quite extensively and deeply by many scholars, and it is not difficult to imagine that the diverse definitions would include various subordinate concepts (Choi \& Hong, 2004; Yu, 1995; Jeong \& Hwang, 2012; Nam, 2004; Westerstahl, 1983; McQuail, 1986). We will not go into detail regarding the definition of fairness in this paper, but will focus more on exploring how the concept of fairness can help us find relevant elements of the sociocultural performance of media organizations. We conceptualize that the importance of media fairness will ultimately relate to how the audience recognizes the output of media organizations especially in the current situation in Korea, as the "trust crisis" of media organizations is so fundamental that it threatens the sustainability of 
many media companies (Rhee \& Choi, 2005). In this light, the trust crisis can be viewed as a failure of media organizations to accomplish sociocultural performance as they failed to realize their goal in terms of the quality of media contents or their effect on the audiences.

The definition of fairness, especially as it is used in connection with news reporting, has been examined quite extensively and deeply by many scholars (Choi \& Hong, 2004; Yu, 1995; Jeong \& Hwang, 2012; Nam, 2004; Westerstahl, 1983; McQuail, 1986). We do not go into detail regarding the definition of fairness here but instead focus more on exploring how the concept of fairness can help us identify relevant elements of media organizations' sociocultural performance. We suggest that the importance of media fairness is ultimately tied to how the audience receives the output of media organizations, especially in the current climate in Korea, where the "trust crisis" threatens the sustainability of many media companies (Rhee \& Choi, 2005). Media organizations' sociocultural performance can be thus conceptualized in terms of the level of trust they acquire from their audience. Measuring readers' and viewers' trust, however, creates another difficulty. Many organizations, including the media itself, conduct surveys to assess readers' and viewers' trust and report the results to the public. Not all data on this issue is equally reliable, so we must carefully choose the data we use as indicators of sociocultural performance. Oftentimes these kinds of surveys do not include all the media organizations in the industry, so the data can be limited. Alternatively, considering that the audience's trust is ultimately connected to loyalty to the organization, it can be measured by subscription rates and viewer ratings.

We now turn to the factors that can influence media organizations' performance.

\section{FACTORS INFLUENCING MEDIA ORGANIZATIONS' PERFORMANCE}

Organizational culture, human resource management, leadership, public service motivation, and performance evaluation have been proposed in previous studies as factors that influence organizational performance (Wolf, 1993; Brewer \& Selden, 2000; Park, Kan, Kwon, \& Kim, 2001; Kwon \& Im, 2003). Brewer and Selden (2000) divide the factors influencing organizational performance into organizational and individual factors. Organizational factors include the nature of organizational culture, level of human resources, quality of leadership, and extent of bureaucratic red tape. Individual factors include the kind of task structure an organization has (nature of compensation, task motivation, public service motivation) and individual capability. In this section, we examine other factors that can influence media organizations' performance. 


\section{Independence}

Independence refers not only to political independence from a governing power but also to economic independence from market power. Political independence is a critical requisite for media organizations to serve the public interest in Korea, considering that there were frequent disputes over fairness during the authoritarian regimes, and even after democratization the question of fairness of media has always been an issue, especially during the period of political transition. Market pressure and media companies' pursuit of profit in the market are also, however, a threat to the independence of media organizations.

The Korea Broadcasting System (KBS), the largest public broadcasting corporation in Korea, was first established as a national television network and its personnel, budget, and programs were regulated by the government. Then, in 1973, after the enactment of Korean Broadcasting System Act, it was reorganized as a public corporation. In the 1980s, KBS's political independence was substantially compromised by the authoritarian regime's control over the media. The Kim Dae-Jung administration enacted the Broadcasting Act of 2000 that reduces the president's power to appoint the head of KBS and secure his tenure. In 2014, the National Assembly passed the amendment of the Broadcasting Act, which requires the KBS head to be the subject of confirmation hearings. However, in spite of many measures for improving the independence of KBS, government regulations still remain, and its independence is often threatened by regulations or political power (Jeong et al., 2008; Choi \& Park, 2009). Even when the press reform became the priority objective in the Roh Mu-hyun administration, which suspended the practices of taking the first edition of newspapers and established joint delivery system, the reform was not viewed as successful in terms of the media's political independence (Shin, 2012). As it can be assumed that media organizations that are not independent from the political power or the government will find it difficult to report fairly about political and social issues, the independence of media organizations seems to be an important factor that influences media organizations' sociocultural performance.

The market is also a critical factor that can threaten the media's independence. Broadcasting companies compete for ratings over the limited sources of advertising revenue and the public's time (Jo \& Park, 2011). In a comprehensive study of the relationship between major newspapers and large advertisers, Bae (2012) claims that advertisers' influence was weak until 1987, but since 2002, newspapers became unilaterally dependent on large advertisers. Kim and Hyeon (2008) argue that although KBS and $\mathrm{MBC}$ are called public broadcasters, their dependency on advertisement revenue is not clearly different from that of private broadcasters. More than half of KBS's 
revenue and MBC's entire revenue comes from advertising sales.

The degree of independence of newspapers and broadcasting organizations influences content, especially its ability to report objectively about the government or large corporations. Bae (2010) reports that most Korean daily newspapers are extremely vulnerable to the pressure of advertisers and that advertisers influence what the newspapers report regarding them. Some newspapers even try, according to him, to utilize news reports as a means of attracting advertisers. Media organizations that are dependent on advertisers will not likely be able to report critically or fairly about those advertisers or the condition of the market that is related to them. Kim (2013) also notes that favorable reports about companies appeared on networks when companies spend more money on advertising, demonstrating the dependency of television networks on advertising revenue.

\section{Diversity}

Another factor that influences media organizations' sociocultural performance is the degree of their diversity. Media content that represents various voices from different social groups and classes is typically regarded as fair and impartial and as complying with media regulations. In this way, diversity can be a factor that affects the audience's trust of media organizations and their content.

The concept of diversity can be classified into social diversity, media diversity, and opinion diversity (Cuilenburg, 2002). Media diversity serves as a channel that reflects social diversity and expresses opinion diversity (Lee \& Bae, 2011). Earlier studies of media diversity first focused on the supply aspect (program types and formats) and society/economy/culture (content diversity, etc.), but have recently shifted their focus to the consumption aspect (user diversity, exposure diversity) (Jeong, 2013).

The concept of media diversity most often invoked by scholars is that proposed by Napoli (2001), which is related to three questions: who makes/distributes contents (diversity of supply sources), what kind of contents are produced (diversity of contents), and who consumes (diversity of exposure). The diversity of supply sources is composed of diversity of ownership and diversity of personnel structure; the diversity of contents comprises diversity of program genres, demographic diversity of figures in programs and diversity of opinions; and the diversity of exposure comprises horizontal exposure diversity (refers to the diversity of programs available during a specific time slot through a specific medium) and vertical exposure diversity (refers to the diversity of programs available in a channel).

Regulators in many countries attempt to promote media diversity, especially supply diversity. For example, regulations pertaining to broadcasting personnel structure in 
the United States and the UK and the limit on television audience share in Germany encourage ownership diversity, and the cross-media summated index that was developed in Korea after the introduction of comprehensive programming channels can be interpreted as an attempt to diversify supply source (Lee \& Bae, 2011).

Content diversity can be measured by the number of pages in a newspaper, by program planning, and by ombudsman activities that can help ensure that various opinions from readers or viewers are heard. In particular, having ombudsmen in the company is a declaration that a newspaper or broadcaster will strictly self-monitor itself, and it can also bridge the gap between the company and its audiences. Ombudsmen or grievance handlers are in charge of duties related to the prevention and relief of damage caused by articles or broadcasts. They investigate whether readers or sources have been injured and can suggest that the organization offer a retraction or compensate for damage if the information reported turns out to be false. In addition, some media organizations make themselves open to readers' opinions by operating an information reception center or complaint/grievance center. Exposure diversity is enhanced by representing or reflecting geographically vulnerable regions and having remediation policies for minorities.

\section{Openness}

With the growth of civil society, public organizations are promoting the participation of external stakeholders through various institutional tools, such as collecting the opinions of interest or civic groups associated with a policy-making or service-provision process. The participation of external stakeholders can ensure procedural publicness, and participation of various classes can ultimately increase the degree of substantive publicness (Jeong, 2010).

Openness is not only a matter of participation on the part of external stakeholders but also of internal stakeholders. The participation of external stakeholders can be measured by whether committees composed of readers or viewers are active, and that of internal stakeholders can be measured by whether labor unions or journalist associations exist and whether their voices are reflected in newspapers or broadcasts. The attributes of media labor unions are much more complex than that of general labor unions due to the unique characteristics of the media industry. Although labor unions in the manufacturing industry are actively with both the market and the government, they are not directly controlled by the state, nor does the state interfere with their activities. However, media labor unions not only deal with employers and the state but also work to address changes in the media environment. Media labor unions function as labor market organizations that protect and promote workers in the media industry and 
pursue the democratization of media by criticizing the state's control and repression. As workers in media organizations determine what kind of news and information are conveyed to the public (Shin, 2012), the existence of labor unions can make a difference in media content and their fairness.

\section{CONCLUSION}

This study categorized the concept of media organizations' performance into economic-industrial performance and sociocultural performance with regard to their distinctiveness, and examined the factors that influence their performance. Economicindustrial performance encompasses media organizations' operations in the market, such as sales revenue. In addition, because their revenue heavily depends on advertisements, newspaper subscriptions or television viewer ratings, which are directly connected to advertisement revenue, these can be used as performance indicators. Sociocultural performance refers to how a media organization fares with respect to its mission. A media organization's sociocultural performance primarily depends on whether it has actually accomplished the goals indicated by relevant laws. In addition, sociocultural performance depends on how the contents of a media organization are recognized by its readers or viewers, which can be identified by media credibility/trust measures that are often conducted by many organizations.

The factors that influence the performance of media organizations are independence, diversity, and openness. Independence includes political independence from government power as well as economic independence from market power. In Korea, the intervention of political and economic powers is perceived as the biggest threat to the ability of media organizations to be objective, and controversies over fairness are regarded as the most critical factor that contributes to the audience's distrust of media organizations.

Diversity is based on the normative demand that media organizations need to serve as channels for expressing various public opinions, which is the most important factor in maintaining and developing democracy. When media contents reflect a variety of opinions of different social groups and classes, they are often recognized to be fair and impartial, and considered to comply with media regulations. The diversity of media contents can affect the audience's trust in the media organizations and their contents.

Openness refers to how extensively and actively media organizations' internal and external stakeholders are participating in the production process of media contents. When the participation of external stakeholders is increased through various institutional tools, such as collecting opinions of interest or civic groups, not only is procedural publicness ensured, but substantive publicness is also known to increase. Likewise, in 
the case of media organizations, the participation of external stakeholders, such as readers and viewers, and that of internal stakeholders, such as journalists and production personnel, can affect the quality of media contents, which can influence the audience's satisfaction with and perceived credibility of media organizations and their contents.

The present study is a preliminary attempt to perform conceptual analysis as groundwork for empirical research. We hope this preliminary examination can provide a foundation for comparative studies of diverse public organizations such as public hospitals, universities, and public enterprises, and can contribute to further theoretical and conceptual discussions about organizational performance.

\section{REFERENCES}

An Gyeongseop. 2008. The effects of organizational culture in public sector on organizational performance. Korean Policy Sciences Review, 12(4): 103-131.

Bae Jungkun. 2010. A study on advertising's influence on newspaper reports. Korean Journal of Journalism \& Communication Studies, 54(6): 103-128.

. 2012. A study on the resource dependence relationship change between daily newspapers and large corporate advertisers. Korean Journal of Journalism \& Communication Studies, 56(4): 265-292.

Boschken, H. L. 1994. Organizational performance and multiple constituencies. Public Administration Review, 54(3): 308-312.

Brewer, G. H., and Selden, S. C. 2000. Why elephants gallop: Assessing and predicting organization performance in federal agencies. Journal of Public Administration Research and Theory, 10(4): 685-711.

Choi Yeongmuk, and Park Seungdae. 2009. The influence of state on the structure of PSB and broadcasting regulatory body: Survey on political independence of broadcasting. Journal of Communication \& Information, 46: 590-626.

Choi Yeongjae, and Hong Seonggu. 2004. Liberty of the press and fairness. Journal of Communication \& Information, 48(6): 326-342.

Chun, Y. H. (2009). 2009. A meta-analysis of public-private distinction research: Sayre's proposition revisited. Korean Journal of Public Administration, 47(2): 61-93.

Cuilenburg, J. V., and McQuail, D. 2003. Media policy paradigm shift: Towards a new communications policy paradigm. European Journal of Communication, 18: 182-207.

Erkkila, Tero. 2007. Governance and accountability: Shift in conceptualization. Public Administration Quarterly, Spring: 1-38. 
Finer, Herman. 1941. Administrative responsibility in democratic government. Public Administration Review, 1(4): 335-350.

Friedrich, Carl Joachim. 1940. Public policy and the nature of administrative responsibility. In C. J. Friedrich and E. S. Mason (eds.), Public Policy. Cambridge, Massachusetts, and London. England: Harvard University Press.

Ha Juyong. 2014. A performance evaluation of the newly licensed 'comprehensive programming' TV channels in Korea: Can they meet the policy goals? Korean Journal of Broadcasting \& Telecommunications Research, Winter: 37-67.

Hoek, Freek, Cor van Montfort, and Cees Vermeer. 2005. Enhancing public accountability in the Netherlands. OECD Journal on Budgeting, 5(2): 69-86.

Hood, C. (1991). A public management for all seasons. Public Administration, 69: 3-19.

Jeong Dongwu, and Hwang Yongseok. 2012. The study on journalistic cognitive attitudes about the concept of impartiality: The integrated model of objectivistic and subjectivistic approaches. Media and Society, 20(3): 120-158.

Jeong Mugwon. 2010. Conceptualization of "public performance" for a multidimensional performance analysis of public organizations: With the focus on Korean quasigovernmental organizations. Journal of Governmental Studies, 16(1): 333-376.

Jeong Yeongho. 2013. Prediction and verification the effectiveness of diversity policies using dynamic model of media diversity. Korean Journal of Journalism \& Communication Studies, 57(1): 216-244.

Jeong Yongjun, Kang Sangheun, Song Jongkil, Yun Hosun, Oh Yongsu, Park Noilk, and Yun Sunmin. 2008. The independence of broadcasting policies and Korea communications commission under the Lee Myong-bak administration. Korean Association for Broadcasting and Communication Studies Seminar and Reports, $5(23)$.

Jeong Jongwon, and Lee Dongyeong. 2012. An exploratory study of politics within an organization: with the focus on an empirical analysis of causal relationship with organizational citizenship behavior, job satisfaction and organizational performance. Korean Public Management Review, 26(3): 261-289.

Jo Hangje, and Park Hongsik. 2011. The politics and economy of Korean television: An exploration on the relationships among the state, the market and civil society. Studies of Broadcasting Culture, 23(1): 41-71.

Kim Daeho. 2011. Global status of Korea's media firms and their future strategies. The Journal of the Korea Contents Association, 11(9): 174-186.

Kim Byeongcheol. 2013. TV advertisers' influences on favorable news reports of TV broadcasters in Korea. Korean Journal of Broadcasting, 27(2): 44-75.

Kim Jinyeong, and Hyeon Jingwon. 2008. Publicness and government expansion: An application to Korean public broadcasting Industry. Korean Journal of Public 
Finance, 1(4): 201-226.

Kim Jinung. 2003. The philosophical and institutional analysis of public interest in broadcasting. Broadcasting \& Communication, 6-13.

2008. Public accountability of terrestrial broadcasting. Korean Association for Broadcasting and Communication Studies Seminar and Reports, 29-47.

Kim Taeryong, and An Huijeong. 2006. The effects of team system on organizational performance. Korean Public Administration Review, 40(4): 303-326.

Kljin, Erik-Hans, and Skelcher, Chris. 2007. Democracy and governance networks: Compatible or not? Public Administration, 85: 587-608.

Korea Press Foundation. 2014. 2014 The Korea press. Seoul: Nanam Communications.

Kwon Gyeongdeuk, and Im Jeongbin. 2003. Determinants of organizational performance in Korean local governments. Korean Public Administration Quarterly, 15(1): $131-154$

Kwon Oseong, Hwang Hyesin, An Hyeokgeun, and Park Seokhui. 2009. A preliminary study on accountability in Korean public institutions. Korean Governance Review, 16(2): 231-261.

Lee Sangsik. 2008. Industrial policies of cable television in Korea. Seoul: Nanam Communications.

Lee Sangwu, and Bae Seonyeong. 2011. Media diversity. Seoul: Communication Books.

McQuail, D. 1986. From bias to objectivity. In McCormark, T. (ed), Studies in Communication: A research manual, 3 (pp. 1-36). Greenwich: JAI Press.

Napoli, P. M. 2001. Foundations of communications policy: Principles and process in the regulation of electronic media. NJ: Hampton Press.

Nam Jaeil. 2004. Objectivistic habitus of Korean newspapers: With the focus on formal realism and strategic ritual. Doctoral dissertation, Graduate School of Journalism \& Mass Communication. Korea University.

Ospina, Sonia, Grau Cunil, and Zaltsman A. 2004. Performance evaluation, public management improvement and democratic accountability: Some lessons from latin America. Public Management Review, 6(2): 229-251.

Park Seokhui. 2010. An analysis of internal customer satisfaction in public corporations from the perspective of accountability. Korean Journal of Public Administration, 48(2): 249-280.

Park Cheono, Kang Jesang, Kwon Gyeongdeuk, and Kim Sangmuk. 2001. A study on the potential productivity of female public servants in Korea. Korean Policy Studies Review, 10(3): 199-224.

Perry, J. L., and Rainey, H. G. 1998. The public-private distinctrion in organization theory: A citique and research strategy. Academy of Management Review, 13: 
89-98.

Rainey, H. G., and Bozemna, B. 2000. Comparing public and private organization: Empirical research and the power of the a priori. Journal of Public Administration Research and Theory, 10: 447-469.

Rhee Junewoong, and Choi Yeongjae. 2005. Causes of the crisis in Korean newspapers: Functional displacement in media use, provision of lower value, and trust crisis. Korean Journal of Journalism \& Communication Studies, 49(5): 5-35.

Roberts, C. Nancy. 2002. Keeping public officials accountable through dialogue: Resolving the accountability paradox. Public Administration Review, 62(6): 658-669.

Romzek, Barbara S., and Dubnick, Melvin J. 1987. Accountability in the public sector: Lessons from the challenger tragedy. Public Administration Review, 47(3): 227-238.

Selden, Sally Coleman, and Sowa, Jessica E. 2004. Testing a multi-dimensional model of organizational performance: Prospects and problems. Journal of Public Administration Research and Theory, 14: 395-416.

Shin Gwangyeong. 2012. Democratization, marketization and media labor movements in Korea. Korean Journal of Communication \& Information, 57: 69-83.

Sorensen, Eva. 2002. Democratic theory and network governance, administrative. Theory and Praxis 24: 693-720.

Yu Jongwon. 1995. A study on the concept of fairness in Korean journalism. Korean Journal of Journalism \& Communication Studies, 33: 137-164.

Yun Seongok. 2013. What is broadcasting's publicness?: An inquiry into theory and practice for policy goal setting. The News Media \& The Law, 12(1): 143-183.

Van Dooren W., Bouckaert, G., and Halligan, J. 2015. Performance management in the public sector (2nd ed.). London and New York: Routledge.

Wang Taegyu. 2007. A study on the influencing factors of organizational performance in the individual level. Korean Review of Organizational Studies, 4(1): 63-90.

Westerstahl, J. 1983. Objective news reporting: General premises. Communication Reserarch, 10(3): 403-424.

Wolf, P. J. 1993. A case survey of bureaucratic effectiveness in U.S. cabinet agencies: Preliminary results. Journal of Public Administration Research and Theory, 3(2): 161-81. 